Supporting information

\title{
Hydrothermal Carbonization of Microalgae-fungal Pellets: \\ Removal of Nutrients from the Aqueous Phase Fungi and \\ Microalgae Cultivation
}

Jie Chen, Lisha Ding, Renfeng Liu, Siyu Xu, Luyi Li, Liwei Gao, Liang Wei, Songqi Leng, Jun Li, Jingjing Li, Lijian Leng*,Wenguang Zhou*

Table of contents of supporting information (4 figures and 1 table, 6 pages)

1. Figure S1 Fourier Transform Infrared profile of hydrochar and feedstock biomass.

2. Figure S2 Thermogravimetric degradation characteristics of hydrochar and feedstock biomass.

3. Figure $\mathbf{S 3}$ (a) Chlorella sp. growth curve in an artificial medium and the $5 \%$ $\mathrm{AP}$;(b) The $\mathrm{pH}$ variation trend of all processes in the $5 \% \mathrm{AP}$. The interpretation of abbreviations in Figures can be seen in Table 1.

4. Figure S4The Chlorella sp. and Penicillium sp. grew in 5\% AP.

5. Table S1 Identification organic matter products in the aqueous phase from the hydrothermal carbonization by gas chromatography-mass spectrometry. 


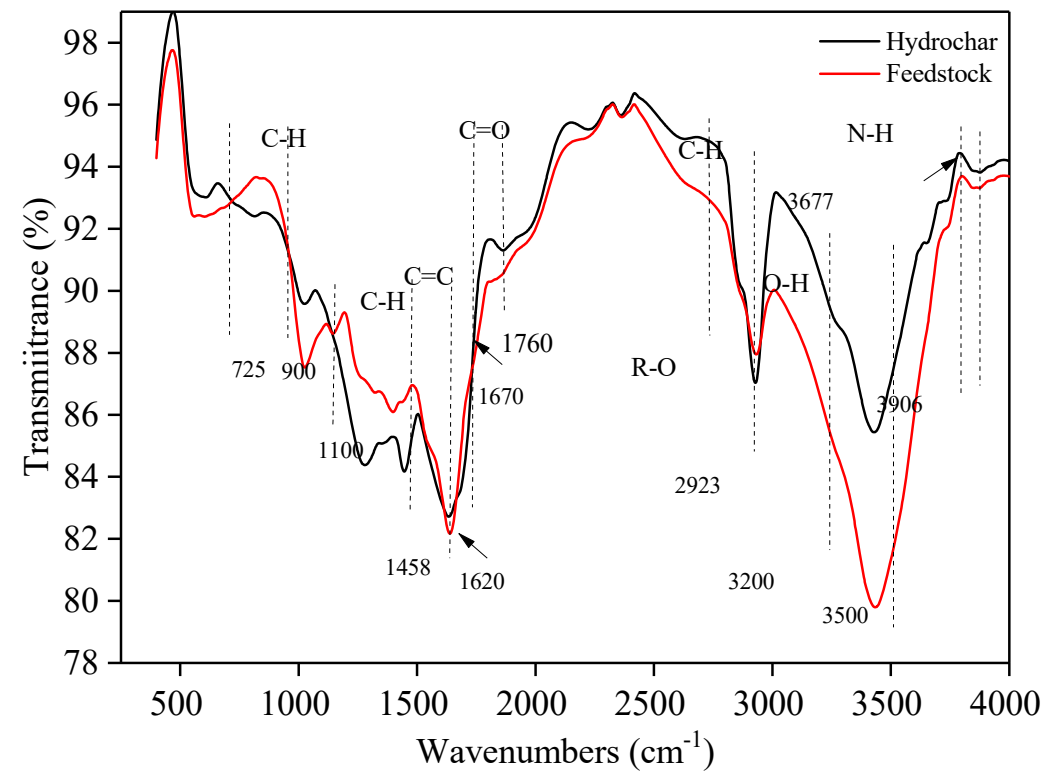

Figure S1 Fourier Transform Infrared profile of hydrochar and feedstock biomass. 

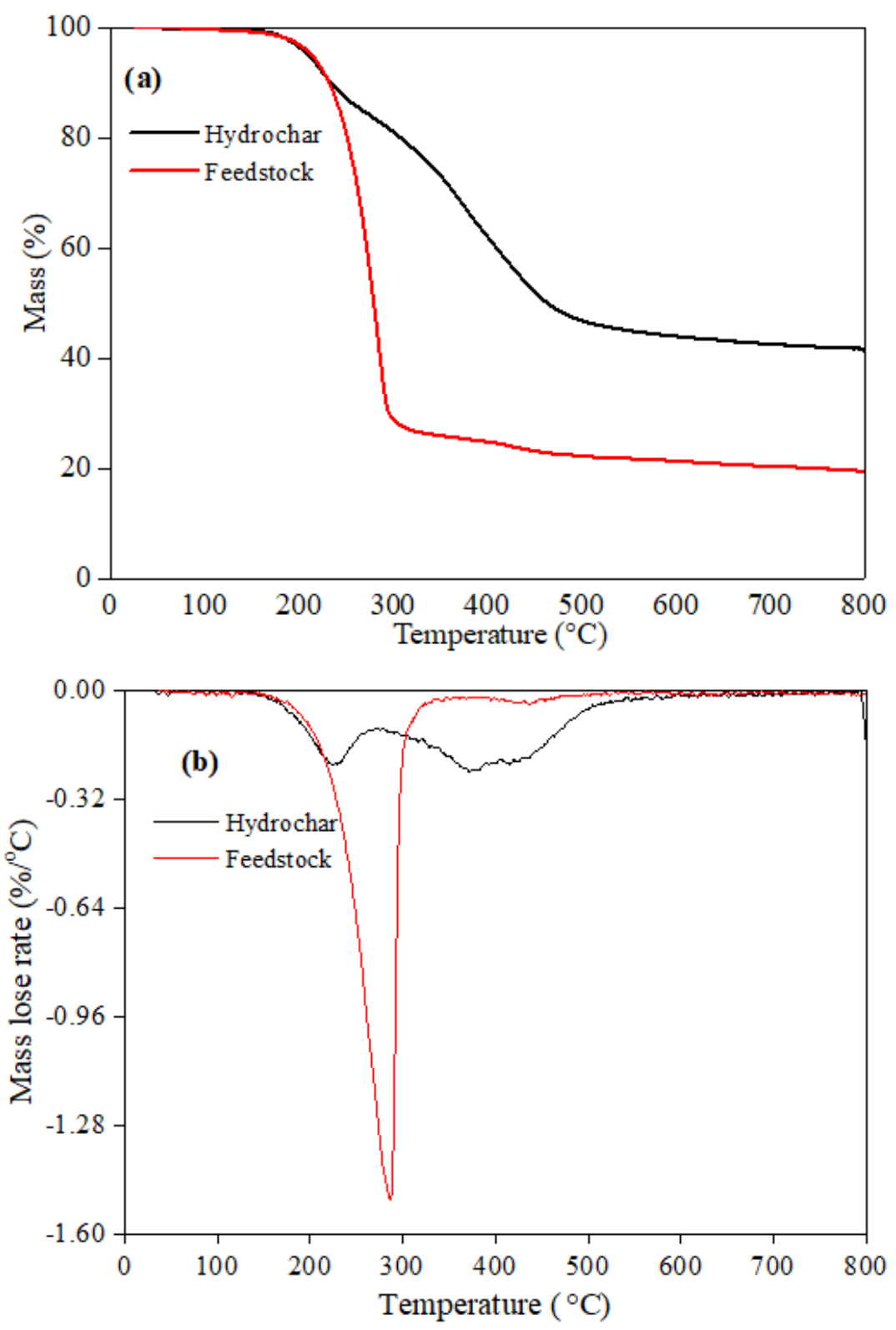

Figure S2 Thermogravimetric degradation characteristics of hydrochar and feedstock biomass. (a) The thermogravimetric analysis (TG) curve of hydrochar and feedstock; (b) The derivative thermogravimetry (DTG) curve of hydrochar and feedstock. 

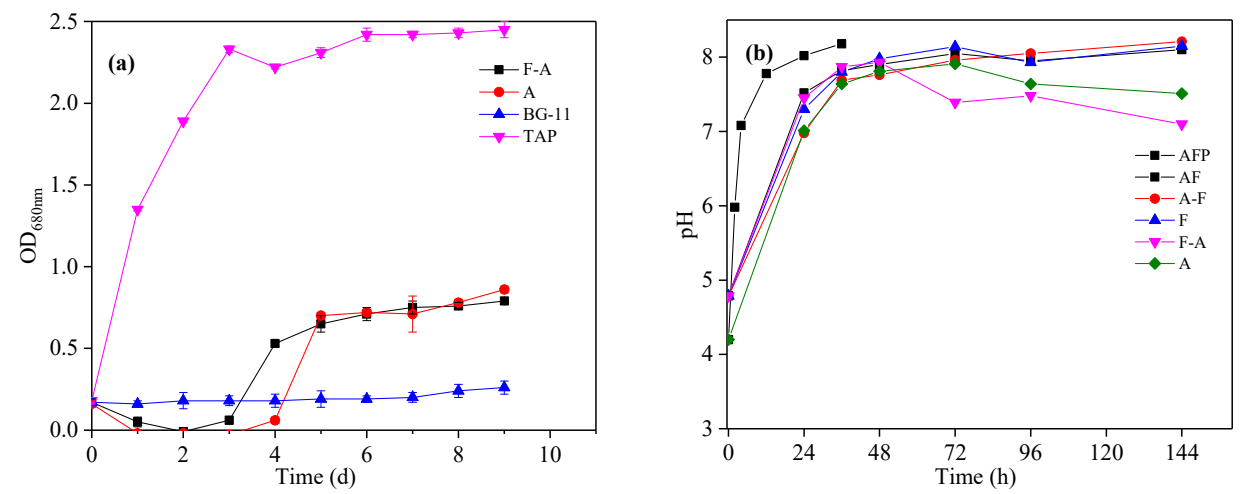

Figure $\mathbf{S 3}$ (a) Chlorella sp. growth curve in an artificial medium and the 5\% AP; (b) The $\mathrm{pH}$ variation trend of all processes in the 5\% AP. The interpretation of abbreviations in Figures can be seen in Table 1. 

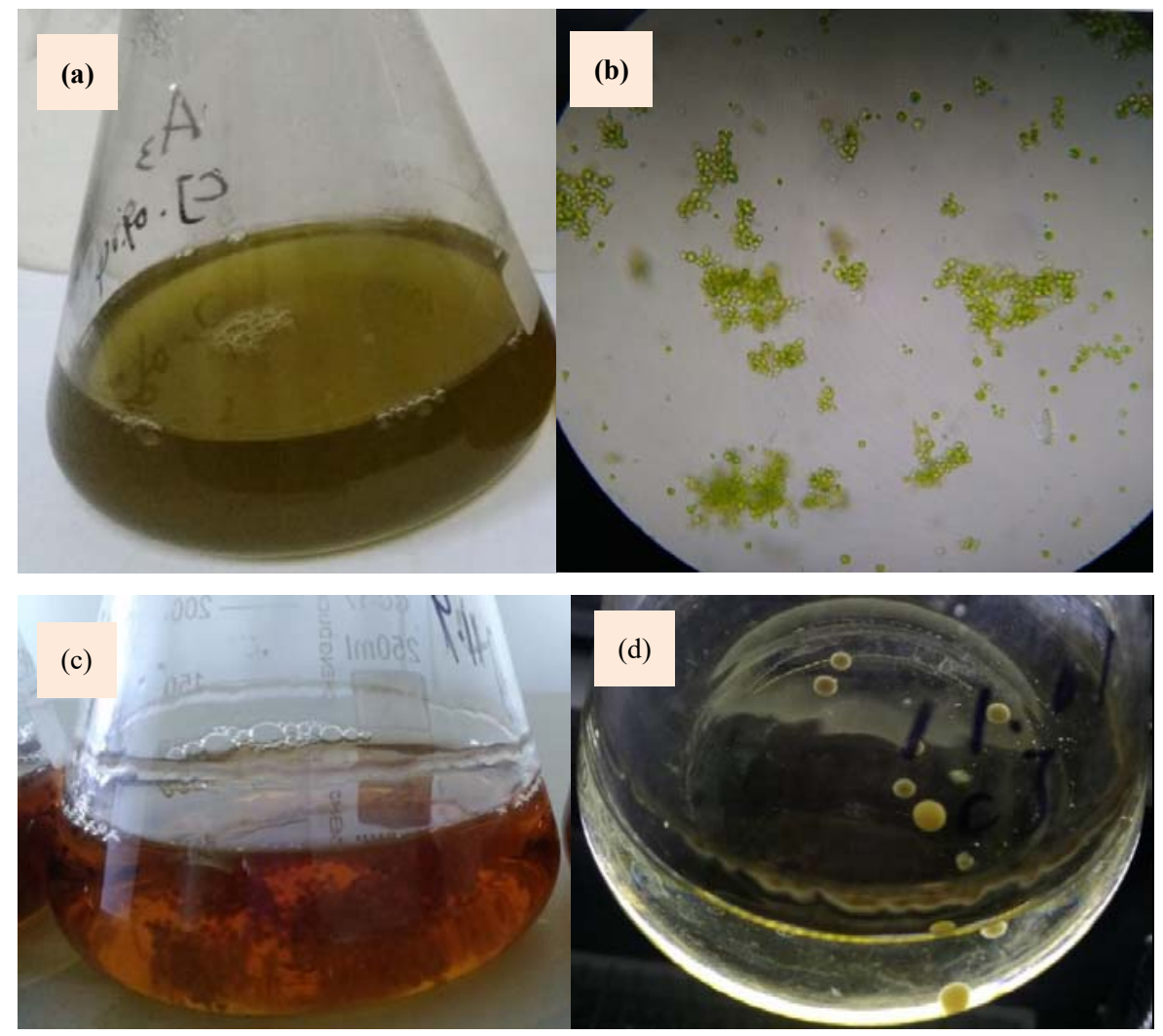

Figure S4 The Chlorella sp.and Penicillium sp. grew in 5\% AP.: (a) The Chlorella sp. culture in 5\% AP; (b) Chlorella sp. reunited; (c) The fungal pellets of Penicillium sp. monoculture in $5 \% \mathrm{AP}$;(d) Microalgae-fungal pellets of co-culture in 5\% AP. 
Table S1 Identification organic matter products in the aqueous phase from the hydrothermal carbonization by gas chromatography-mass spectrometry.

\begin{tabular}{|c|c|c|c|c|c|c|c|}
\hline $\begin{array}{l}\text { Retention } \\
\text { time (min) }\end{array}$ & Compound & Structure & $\begin{array}{l}\text { Peak } \\
\text { Area } \\
(\%)\end{array}$ & \multicolumn{2}{|c|}{$\begin{array}{l}\text { Retention } \\
\text { time (min) }\end{array}$} & \multirow[t]{2}{*}{ Structure } & $\begin{array}{l}\text { Peak } \\
\text { Area } \\
(\%)\end{array}$ \\
\hline 7.03 & Pyridine & & 0.46 & 11.65 & $\begin{array}{c}\text { Methyl } \\
\text { cyclopentenolone }\end{array}$ & & 10.14 \\
\hline 7.16 & 2-picolinic acid & & 0.45 & 12.04 & $\begin{array}{l}\text { 2-ethyl-6-methyl } \\
\text { pyrazine }\end{array}$ & & 1.27 \\
\hline 7.80 & Pyrazine & & 3.45 & 12.18 & $\begin{array}{l}\text { 2-ethyl-5-methyl } \\
\text { pyrazine }\end{array}$ & & 1.82 \\
\hline 7.87 & Pyrimidine & & 6.99 & 12.47 & $\begin{array}{c}\text { 2,3,5-trimethylp } \\
\text { yrazine }\end{array}$ & & 2.94 \\
\hline 9.10 & 2-methylpyrazine & & 7.72 & 12.63 & $\begin{array}{l}\text { 2-ethyl-5-methyl } \\
\text { pyridine }\end{array}$ & & 3.49 \\
\hline 9.15 & $\begin{array}{l}\text { 2-Methylpyrimid } \\
\text { ine }\end{array}$ & & 9.72 & 14.48 & Acetic acid & & 1.32 \\
\hline 9.70 & L-lactic acid & & 1.12 & 15.09 & 2-acetylfuran & & 1.63 \\
\hline 9.75 & $\begin{array}{l}\text { 3-hydroxy-2-buta } \\
\text { none }\end{array}$ & & 1.36 & 15.20 & $\begin{array}{l}\text { 3-methyl-2-cycl } \\
\text { openten-1-one }\end{array}$ & & 2.50 \\
\hline 10.48 & $\begin{array}{l}\text { 2,5-dimethylpyra } \\
\text { zine }\end{array}$ & & 8.07 & 15.70 & $\begin{array}{l}\text { 2,3-dimethyl-2-c } \\
\text { yclopentenone }\end{array}$ & & 1.26 \\
\hline 10.64 & $\begin{array}{l}\text { 2,6-dimethylpyra } \\
\text { zine }\end{array}$ & & 4.00 & 17.86 & $\begin{array}{c}\Gamma \text {-hydroxybutyric } \\
\text { acid }\end{array}$ & & 1.72 \\
\hline 10.80 & 2-ethylpyrazine & & 3.19 & 19.46 & Isovaleric acid & & 2.66 \\
\hline 11.10 & $\begin{array}{l}\text { 2,3-dimethylpyra } \\
\text { zine }\end{array}$ & & 3.89 & 23.79 & 2-pyrrolidone & & 2.79 \\
\hline 11.34 & $\begin{array}{c}\text { 2-cyclopentenon } \\
\mathrm{e}\end{array}$ & & 1.35 & 24.26 & $\begin{array}{l}\text { 1-methoxy-1,3-c } \\
\text { yclohexadiene }\end{array}$ & & 1.17 \\
\hline 11.55 & $\begin{array}{l}\text { 2-Hydroxy-3-pen } \\
\text { tanone }\end{array}$ & & 1.57 & 27.22 & $\begin{array}{c}\text { 3-Isobutyl-2,3,6,7, } \\
\text { 8,8a-hexahydropy } \\
\text { rrolo[1,2-a]pyrazi } \\
\text { ne-1,4-dione }\end{array}$ & & 6.63 \\
\hline
\end{tabular}

